\title{
РАЦИОНАЛЬНАЯ ТЕХНОЛОГИЯ УТИЛИЗАЦИИ ТЕПЛОТЫ ТУРБОКОМПРЕССОРНЫХ СТАНЦИЙ
}

\author{
Г. С. Олишевский, И. Г. Олишевский
}

Наџиональный технический университет «Днепровская политехника», пр. Дмитрия Яворницкого, 19, г. Днепр, 49005, Украина, e-mail: olishevskiyg@ukr.net

\begin{abstract}
Аналітично проаналізовано різноманітні технології утилізації теплоти турбокомпресорних станцій і обгрунтовано вибір їх найбільш раціональних варіантів та значень проміжних температур нагріву води між охолоджувачами повітря турбокомпресора.

Ключові слова: тепловий насос, повітряний турбокомпресор, утилізація теплоти, холодоагент, охолоджувач повітря, коефіціснт перетворення енергії, система опалення, економія палива.
\end{abstract}

Analytical analysis of various technologies for heat recovery of turbocharger stations and justified their choice of the most rational options and values of intermediate temperatures of water heating between air coolers of a turbocharger.

Keywords: Heat Pump, Air Turbocharger, Heat Recovery, Cold-agent, Air-cooler, Coefficient of Transformation of Energy, System of Heating, Fuel Saving.

Аналитически проанализированы различные технологии утилизации теплоты турбокомпрессорных станций и обоснован выбор наиболее рациональных вариантов и значений промежуточных температур нагрева воды между воздухоохладителями турбокомпрессора.

Ключевые слова: тепловой насос, воздушный турбокомпрессор, утилизация теплоты, хладагент, воздухоохладитель, коэффициент преобразования энергии, система отопления, экономия топлива.

Введение. В настоящее время одной из актуальных проблем является проблема энергосбережения. Данная проблема обусловлена тем, что потребление энергии и неблагоприятное влияние на окружающую среду увеличиваются, производство энергии осуществляется недостаточно эффективно, а запасы основных топливно-энергетических ресурсов природного происхождения уменьшаются. Необходимо не только потреблять меньше энергии, а использовать ее наиболее полно в каждом конкретном случае, уменьшая неизбежные в любом техническом процессе выбросы во внешнюю среду. Можно сказать, что эффективность использования энергии является индикатором научнотехнического уровня и экономического потенциала страны [4].

Существуют различные мощные энергетические установки, в которых происходят значительные выбросы тепловой энергии в окружающую среду. Это конденсационные электростанции [1], силовые трансформаторы высокой мощности [2], мощные установки кондиционирования шахт и крупных объектов, а также другие высокоэнергетичные установки и системы.
По этим установкам разработаны либо разрабатываются технические решения по утилизации тепловой энергии, выбрасываемой в окружающую среду. Как правило, данная энергия используется для местных систем отопления и горячего водоснабжения. При этом используются различные методы, в том числе и нетрадиционные, такие как применение тепловых насосов, гелиоустановок и другого оборудования.

Авторами решено проанализировать возможности различных способов утилизации теплоты на таких высокомощных установках как воздушные турбокомпрессоры шахт. Данные установки используются в системах пневмопривода, применяемых на шахтах, относящихся к категории взрывоопасных. В применяемых на данный момент системах охлаждения турбокомпрессоров все тепло, воспринимаемое охлаждающей водой, отводится в окружающую среду. Величина отводимой теплоты может доходить до двух и более МВт. При этом установки имеют практически круглосуточный режим работы, что важно для функционирования системы отопления и горячего водоснабжения. 
Поэтому поиск эффективных технологий утилизации тепловой энергии мощных энергетических установок для ее использования в системах отопления зданий является актуальным.

Постановка задачи. Задачей проведения исследования является анализ эффективности различных технологий и схем утилизации тепловой энергии мощных воздушных турбокомпрессорных установок шахт с последующим обоснованием наиболее рациональной из них для использования в системе отопления административно-бытовых зданий.

Методы исследования. Были использованы методы анализа и численного моделирования, реализованные в приложениях пакета Mathcad.

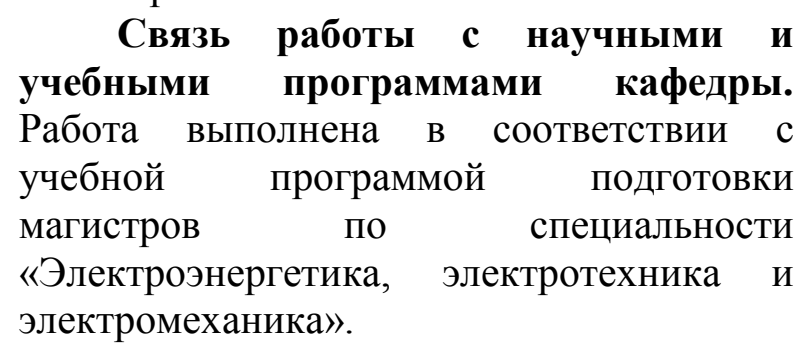

Результаты и их обсуждение. В качестве исследуемого объекта был выбран воздушный турбокомпрессор К-500, получивший широкое распространение на шахтах. При сжатии воздуха в ступени турбокомпрессора происходит существенное повышение его температуры. В свою очередь, дальнейшее сжатие воздуха при повышенной температуре ведет к неоправданным дополнительным затратам мощности привода компрессора. Поэтому между секциями турбокомпрессора применяют промежуточное охлаждение сжатого воздуха. Водяная система охлаждения турбокомпрессора К-500 представляет собой два промежуточных и концевой воздухоохладители, в которых охлаждающая вода нагревается до $28{ }^{\circ} \mathrm{C}$ в соответствии с требуемой конечной температурой сжатого воздуха.

Поскольку температура воздуха при сжатии в ступенях турбокомпрессора достигает значений $90 \ldots 100^{\circ} \mathrm{C}$ и более, то было решено разделить каждый воздухоохладитель на две части. В первой части можно было бы нагревать воду до требуемой температуры, используя лишь часть отводимой в воздухоохладителе теплоты. В свою очередь, во второй части каждого теплообменника происходит окончательное охлаждение сжатого воздуха до конечного значения $35^{\circ} \mathrm{C}$.

$$
\text { Таким образом, используя }
$$

разработанную автоматизированную методику (рис. 1), была проанализирована возможность последовательного нагрева охлаждающей воды до $85^{\circ} \mathrm{C}$ в первых частях всех трех воздухоохладителей (рис. 2) и определены промежуточные температуры воды между воздухоохладителями $\left(50{ }^{\circ} \mathrm{C}\right.$ и $\left.73{ }^{\circ} \mathrm{C}\right)$, соответствующие максимальной тепловой мощности системы отопления (570 кВТ) из условия равенства расходов воды в рассматриваемых трех частях воздухоохладителей, что соответствует $31 \%$ всей отводимой теплоты в компрессоре (1862 кВт).

Данная схема оказалась более выгодной, чем схема нагрева воды сначала в первом промежуточном воздухоохладителе с последующим нагревом параллельно в двух оставшихся воздухоохладителях (рис. 3). При этом была определена рациональная промежуточная температура воды между данными ступенями нагрева $\left(54{ }^{\circ} \mathrm{C}\right)$. Однако полученная тепловая мощность оказалась на четверть меньше, чем в схеме последовательного нагрева в трех воздухоохладителях (423 кВт). При этом в данных схемах не затрачиваются дополнительные энергоресурсы.

Были исследованы возможности применения теплового насоса в рассматриваемой системе. Тепловые насосы (ТН) широко применяются для теплоснабжения, а также кондиционирования жилых и административных зданий в различных странах и получают все большее распространение в Украине.

Принцип действия теплового насоса заключается в заборе теплоты от различных низкопотенциальных (низкотемпературных) источников энергии c последующей трансформацией в 
высокотемпературную тепловую энергию и передаче ее потребителю. При этом затрачивается энергия на привод компрессора теплового насоса. В нашем случае в качестве низкопотенциального источника энергии выступает нагретая охлаждающая вода, температуру которой мы можем принимать в самых широких пределах.

Была рассмотрена последовательная схема подключения теплового насоса к потоку нагретой воды системы охлаждения турбокомпрессора (рис. 4).

Были исследованы случаи для различных значений температур воды, поступающей в испаритель теплового насоса из трех воздухоохладителей одновременно. Проанализировав данные варианты с помощью автоматизированной методики, реализованной в среде Mathcad, был установлен рост тепловой мощности системы отопления с понижением температуры нагреваемой воды на входе в тепловой насос, так как при этом увеличивался расход воды в системе и, соответственно, тепловая энергия, полученная в воздухоохладителях (табл. 1). Однако при этом существенно росли затраты энергии на привод компрессора в тепловом насосе (более 0,5 МВт при температуре воды на входе в тепловой насос $30^{\circ} \mathrm{C}$ ). Поэтому решено было остановиться на варианте с температурой воды $65^{\circ} \mathrm{C}, \quad$ что соответствует тепловой мощности системы отопления 976 кВт и, соответственно, мощности привода компрессора 92 кВт. То есть применение теплового насоса в схеме утилизации теплоты воздушного турбокомпрессора позволяет практически удвоить тепловую мощность системы отопления зданий при сравнительно небольших энергетических затратах на привод компрессора теплового насоса. Однако применение схемы утилизации теплоты без теплового насоса не требует дополнительных затрат энергии при обеспечении существенной тепловой мощности системы отопления.

Характеристики теплового насоса определялись на основе базовых холодильных циклов, рассмотренных ранее в работе [3].

В качестве хладагента был использован широко распространенный хладагент - фреон - 11 .

При этом на основании $\mathrm{p}$, i-диаграммы данного фреона были описаны в виде функций от температуры конденсации $\mathrm{t}_{\mathrm{k}}$ все процессы для различных режимов теплового насоса.

Результаты сравнительных исследований степени утилизации теплоты турбокомпрессора для различных схем представлены на рис. 5.

Таким образом, за счет утилизации тепловой энергии воздушной турбокомпрессорной установки можно обеспечить тепловой энергией систему отопления и горячего водоснабжения как административно-бытовых зданий шахты, так и других строений. При этом существующие котельные могут выступать в качестве резерва на случай аварийной ситуации.

\section{Выводы.}

1. Используя разработанную автоматизированную методику, было проанализировано и определено, что применение схемы последовательного нагрева охлаждающей воды в специальных частях воздухоохладителей позволяет использовать для нужд системы отопления свыше $\quad 30 \%$ количества теплоты, отводимой в турбокомпрессоре К-500 при максимальной температуре горячей воды $85^{\circ} \mathrm{C}$. Показано, что данная схема является наиболее эффективной из всех подобных, не использующих дополнительные источники теплоты.

2. Обоснована возможность применения теплового насоса, подключенного последовательно к потоку нагретой воды из системы охлаждения турбокомпресора, и определена температура нагретой воды на входе в ТН, принятая равной $65^{\circ} \mathrm{C}$ из условия рациональных затрат мощности компрессора теплового насоса с удвоением тепловой мощности системы отопления зданий по сравнению со схемой утилизации теплоты без ТН. 


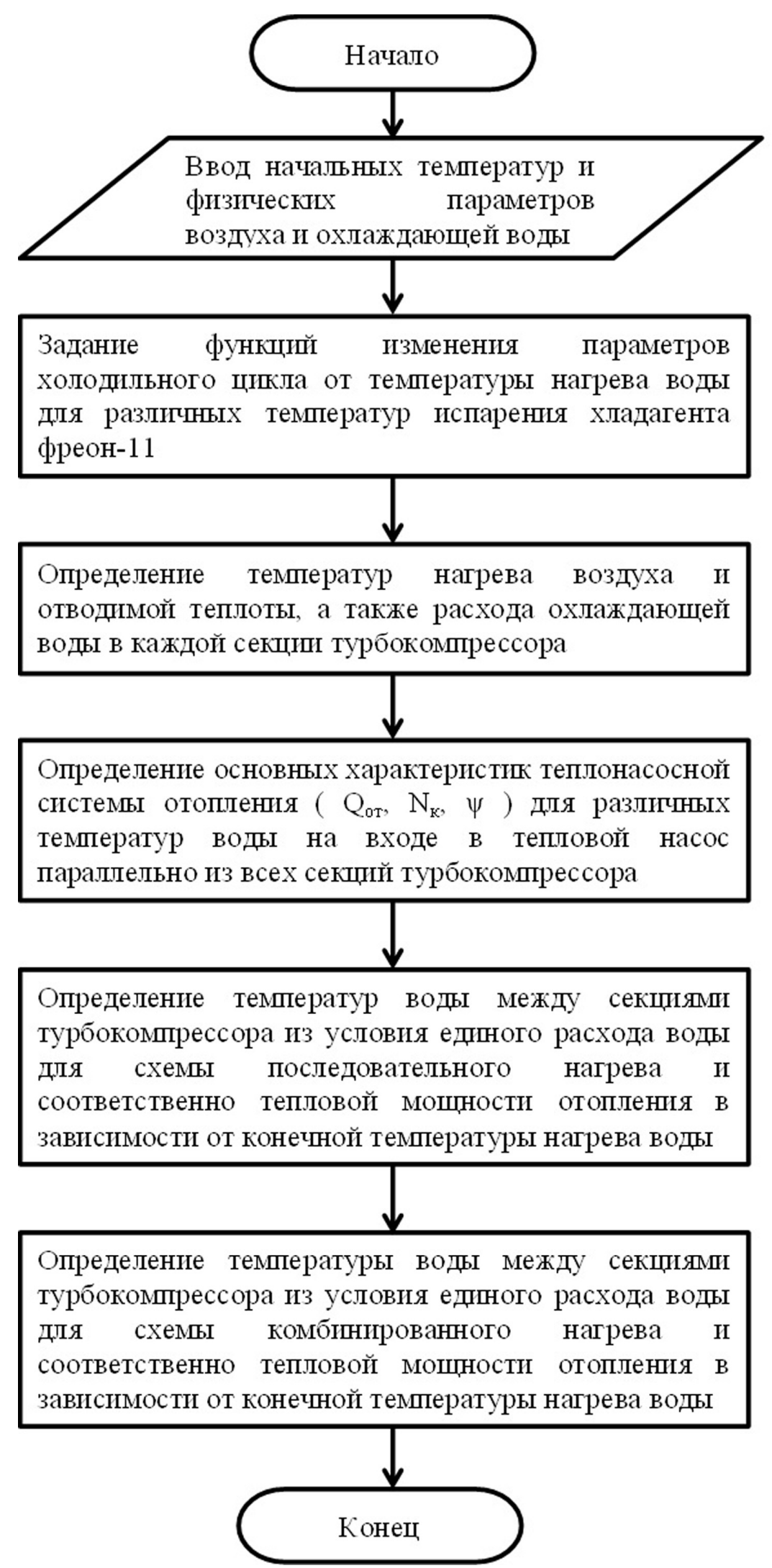

Рис. 1. Блок-схема автоматизированной методики расчета 


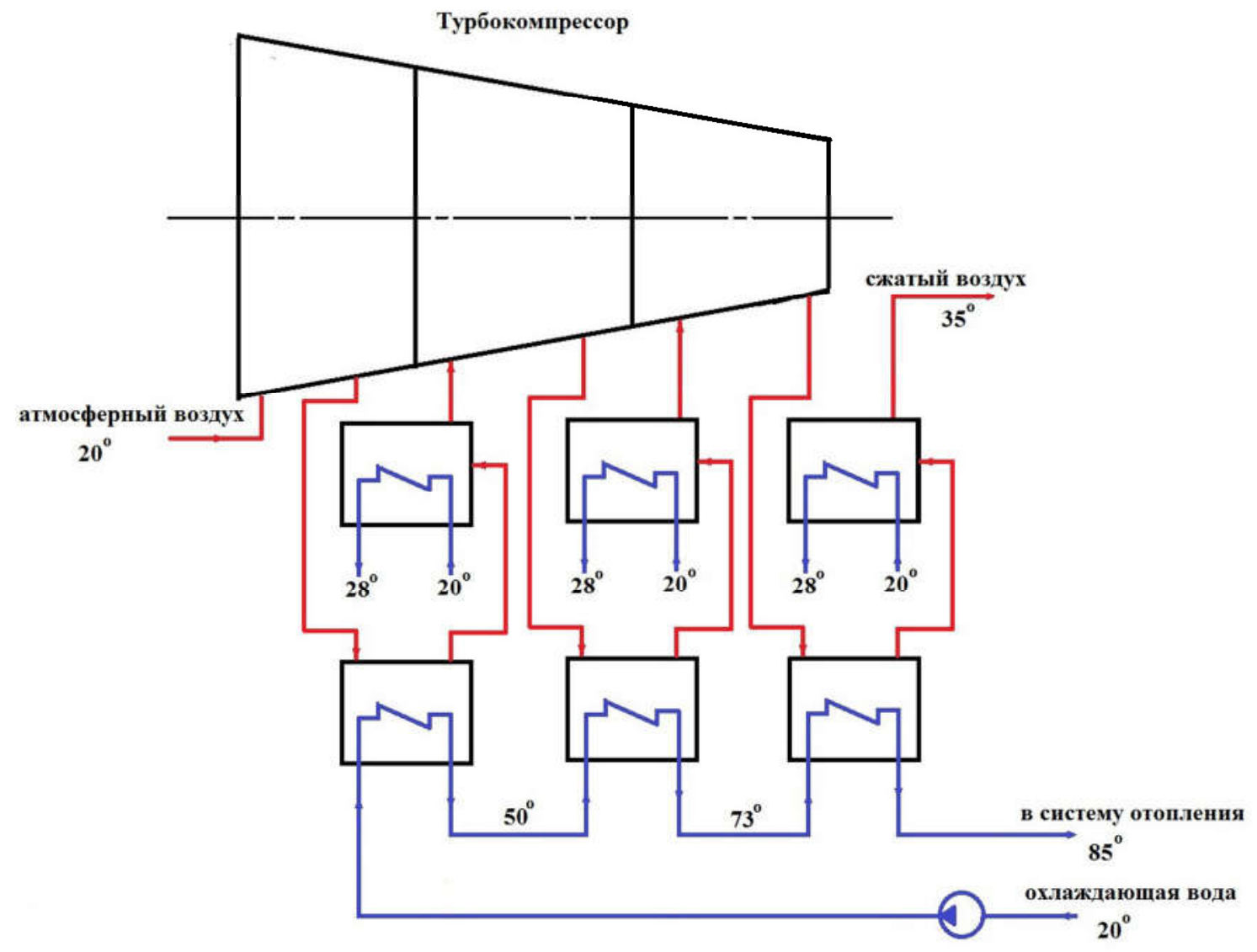

Рис. 2. Схема последовательного нагрева охлаждающей воды

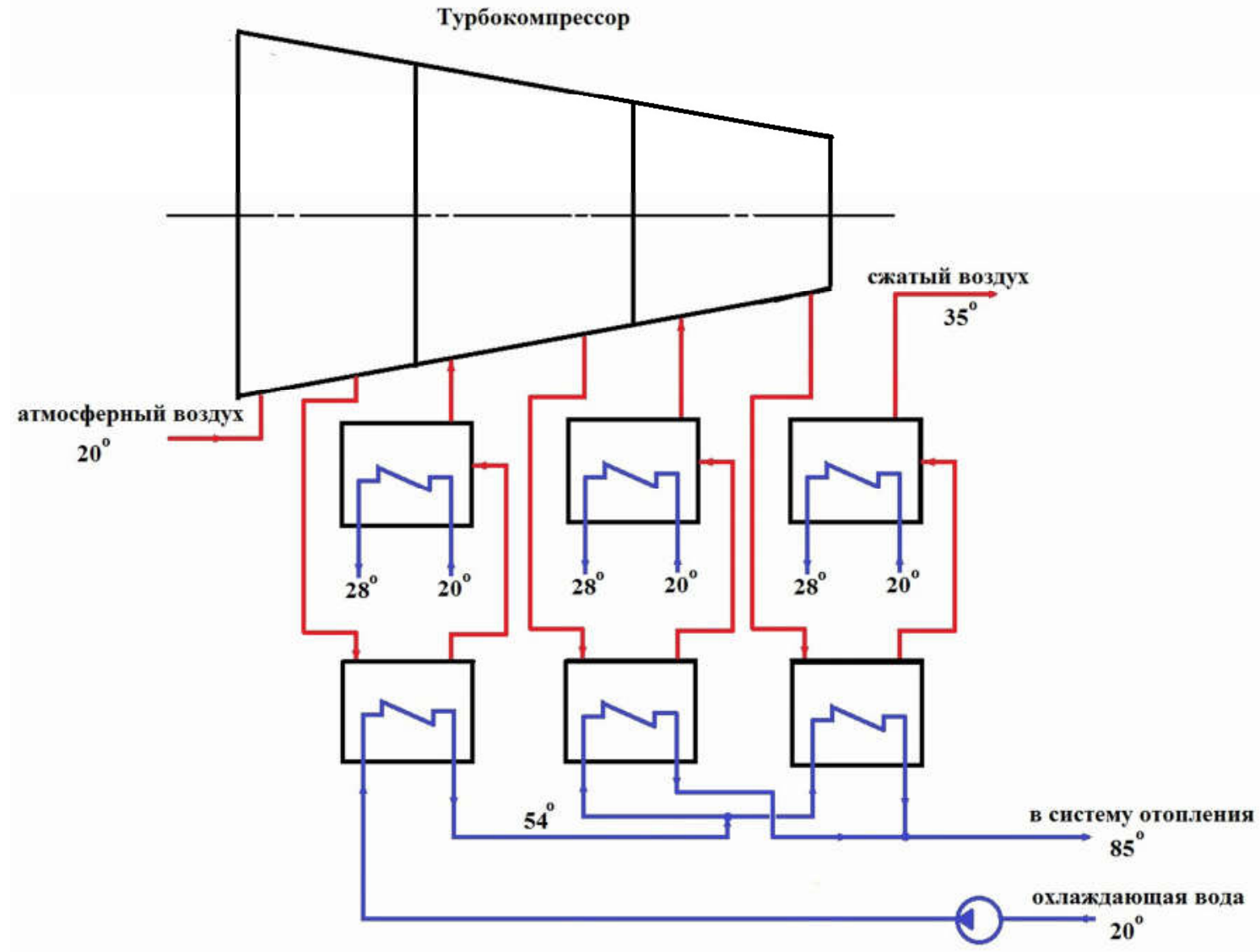

Рис. 3. Схема комбинированного нагрева охлаждающей воды 


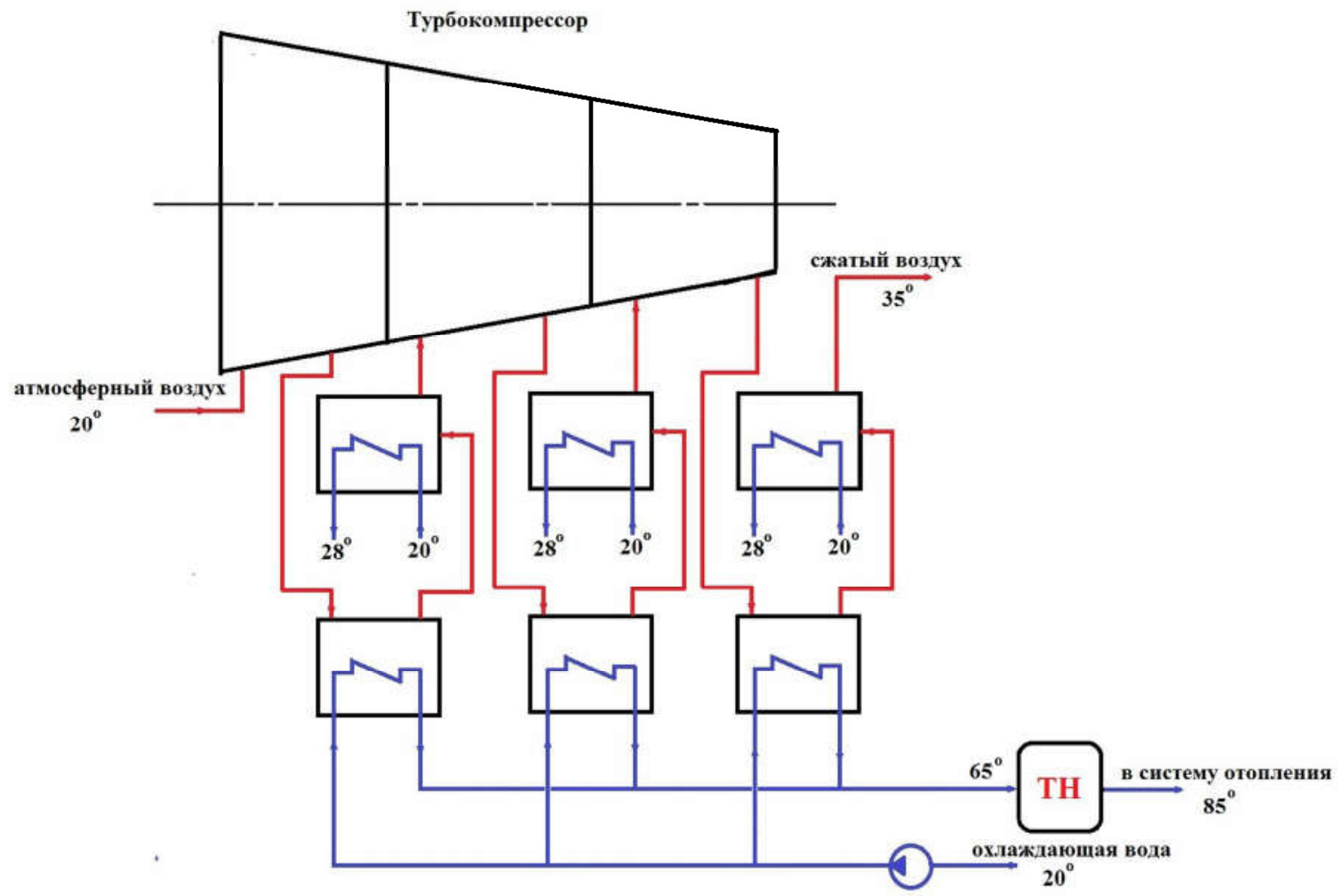

Рис. 4. Схема нагрева охлаждающей воды с применением теплового насоса

Параметры теплонасосной установки

\begin{tabular}{|l|l|l|l|}
\hline Температура воды на входе $\mathrm{t},{ }^{\circ} \mathrm{C}$ & 30 & 50 & 65 \\
\hline Мощность компрессора $\mathrm{N}_{\mathrm{K}}, \mathrm{KBT}$ & 654,13 & 251,25 & 92,30 \\
\hline Тепловая мощность $\mathrm{Q}_{\mathrm{or}}, \mathrm{\kappa BT}$ & 2525 & 1577 & 976 \\
\hline Коэффициент преобразования $\psi$ & 5,0 & 8,2 & 13,7 \\
\hline
\end{tabular}

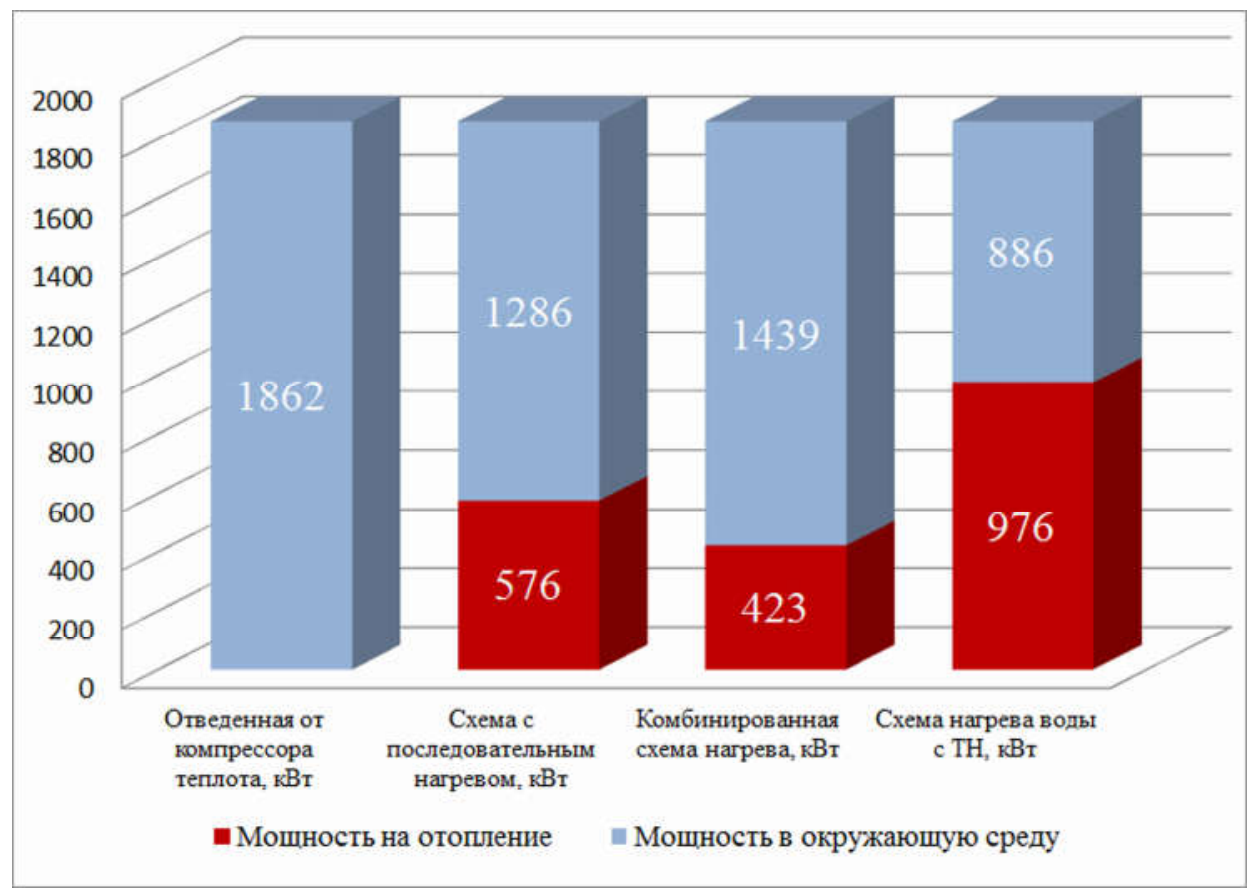

Рис. 5. Сравнительный анализ энергоэффективности различных схем утилизации теплоты турбокомпрессора К-500 
3. Результаты исследований доказали возможность применения эффективных технологий утилизации тепловой энергии мощных воздушных турбокомпрессорных установок как без ТН, так и с ними. При этом разработанная автоматизированная методика показывает пути и перспективы автоматизации и компьютеризации управления подобными технологиями на практике.

\section{Библиографические ссылки}

1. Олишевский Г.С., Олишевский И.Г. Обоснование применения теплонасосного оборудования для теплофикационного режима конденсационных электростанций. Вісник Дніпропетровського університету. Серія: Ракетнокосмічна техніка. 2014. № 4. Т. 22. вип. 18(2). C. 135-140. URL: https://drive.google. com/file/d/1cW8-1RijvKdge-CZ3QAdPcXE$\underline{\mathrm{rASPxqV} / \text { view }}$ (дата звернення: 25.05.2018).
2. Олишевский Г.С., Олишевский И.Г. Обоснование применения теплонасосного оборудования для утилизации тепловых потерь в силовых трансформаторах большой мощности. Вісник Дніпропетровського університету. Серія: Ракетно-космічна техніка. 2015. № 4. Т. 23. Вип. 18(1). С. 131-136. URL: http://nbuv.gov.ua/UJRN/vdurkt 2015 23 18(1) 22 (дата звернення: 25.05.2018).

3. Олишевский И.Г. Обоснование рациональной схемы теплонасосной системы отопления. Механіка гіроскопічних систем. 2015. Вип. 30. С. 2635. URL: http://nbuv.gov.ua/UJRN/mgs 2015 305 (дата звернення: 25.05.2018).

4. Разумний Ю.Т., Заїка В.Т., Степаненко Ю.В. Енергозбереження : навч. посіб. Дніпропетровськ : Національний гірничий університет, 2005. $166 \mathrm{c}$.

\title{
УДК 621.454.2.046.4:662.75
}

\section{ИСПОЛЬЗОВАНИЕ ЧИСЛЕННОГО МОДЕЛИРОВАНИЯ ПРИ РАСЧЕТЕ ОСТАТКОВ КОМПОНЕНТОВ ТОПЛИВА}

\author{
И.Н. Орлянская, О.М. Иванов \\ Государственное предприятие «Конструкторское бюро «Южное» им. М.К. Янгеля», \\ ул. Криворожская, 3, г. Днепр, 49008, Украина, \\ e-mail: innaorlyanskaya@gmail.com,oleg-ivn@ukr.net
}

\begin{abstract}
Проведено порівняльний аналіз результатів визначення залишків компонентів у системі живлення двома методами: експериментальним та чисельним. Експериментально залишок визначали на масштабній моделі, чисельно - використовуючи програмний продукт ANSYS (CFX). Надано рекомендації щодо налаштування програмного продукту для отримання задовільної збіжності 3 експериментальними даними.

Ключові слова: забірний пристрій, система живлення, залишки компонентів палива, гідравлічний залишок, ANSYS, FluidFlow, CFX.
\end{abstract}

Analysis comparison of the results of the determination of the propellant residual in the propellant supply system by two methods: experimental and numerical was spent. Experimentally, the propellant residual was determined by the scale model. The propellant residual was determined numerically using ANSYS (CFX) software. Recommendations are given for setting up the software product to obtain satisfactory convergence with experimental data.

Keywords: intake device, propellant supply system, propellant residuals, hydraulic residual, ANSYS, Fluid Flow, CFX.

Проведен сравнительный анализ результатов определения остатка компонента в системе питания двумя методами: экспериментальным и численным. Экспериментально остаток определялся на масштабной модели, численно - используя программный продукт ANSYS (CFX). Даны рекомендации по настройке программного продукта для получения удовлетворительной сходимости с экспериментальными данными.

Ключевые слова: заборное устройство, система питания, остатки компонентов топлива, гидравлический остаток, ANSYS, FluidFlow, CFX. 